\title{
Geodetic Monitoring of the Variable Surface Deformation in Latin America
}

\author{
Laura Sánchez and Hermann Drewes
}

\begin{abstract}
Based on 24 years of high-level GNSS data analysis, we present a sequence of crustal deformation models showing the varying surface kinematics in Latin America. The deformation models are inferred from GNSS station horizontal velocities using a leastsquares collocation approach with empirically determined covariance functions. The main innovation of this study is the assumption of continuous surface deformation. We do not introduce rigid microplates, blocks or slivers which enforce constraints on the deformation model. Our results show that the only stable areas in Latin America are the Guiana, Brazilian and Atlantic shields; the other tectonic entities, like the Caribbean plate and the North Andes, Panama and Altiplano blocks are deforming. The present surface deformation is highly influenced by the effects of seven major earthquakes: Arequipa (Mw8.4, Jun 2001), Maule (Mw8.8, Feb 2010), Nicoya (Mw7.6, Sep 2012), Champerico (Mw7.4, Nov 2012), Pisagua (Mw8.2, Apr 2014), Illapel (Mw8.3, Sep 2015), and Pedernales (Mw7.8, Apr 2016). We see very significant kinematic variations: while the earthquakes in Champerico and Nicoya have modified the aseismic deformation regime in Central America by up to 5 and $12 \mathrm{~mm} / \mathrm{a}$, respectively, the earthquakes in the Andes have resulted in changes of up to $35 \mathrm{~mm} / \mathrm{a}$. Before the earthquakes, the deformation vectors are roughly in the direction of plate subduction. After the earthquakes, the deformation vectors describe a rotation counter-clockwise south of the epicentres and clockwise north of the epicentres. The deformation model series reveals that this kinematic pattern slowly disappears with post-seismic relaxation. The numerical results of this study are available at https://doi.pangaea.de/10.1594/PANGAEA.912349 and https://doi.pangaea.de/10.1594/PANGAEA.912350.
\end{abstract}

\section{Keywords}

Caribbean · Crustal deformation · Earth surface kinematics · Latin America - SIRGAS . Station velocity model VEMOS

\section{Introduction}

Geodetic reference frames comprise coordinates of station positions at a certain epoch and constant velocities describing a secular station motion. In active seismic regions, strong

L. Sánchez $(\bowtie) \cdot H$. Drewes

Technische Universität München, Deutsches Geodätisches

Forschungsinstitut (DGFI-TUM), München, Germany

e-mail:1m.sanchez@tum.de; h.drewes@tum.de earthquakes cause large displacements of station positions and velocity changes disabling the use of such coordinates over any time periods. The continuous representation of station positions between different epochs requires the computation of reliable station velocity models. Whit these models, we can monitor the kinematics of reference frames, determine transformation parameters between pre-seismic and post-seismic (deformed) coordinates, and interpolate surface motions arising from plate tectonics or crustal deformations in areas where no geodetic stations are established. In the particular case of Latin America, the reference frame is 
called SIRGAS (Sistema de Referencia Geocéntrico para las Américas; cf. SIRGAS 1997) and it is a regional densification of the global International Terrestrial Reference Frame (ITRF; Petit and Luzum 2010). The first SIRGAS realisation was established by a GPS (Global Positioning System) observation campaign in May 1995 (SIRGAS 1997). It comprised 58 stations covering all South America. This network was measured again in May 2000 and it was extended to Central and North America including 184 stations (Drewes et al. 2005). Since 2000, the Latin American geodetic reference network is materialised (and frequently extended) by continuously operating GNSS (GPS+GLONASS) stations (Brunini et al. 2012; Sánchez et al. 2013, 2015; Cioce et al. 2018). As the western margin of Latin America is one of the seismically most active regions in the world, the maintenance of the SIRGAS Reference Frame implies the frequent computation of present-day (updated) surface deformation models. Such models were computed in 2003 (Drewes and Heidbach 2005), 2009 (Drewes and Heidbach 2012), 2015 (Sánchez and Drewes 2016), and 2017 (this paper). Here, we present the computation of the deformation model 2017 and its comparison with the previous models to show the very significant variations of the surface kinematics in Latin America during the past 15 years.

\section{$2 \quad$ Surface-Kinematics Modelling Based on GNSS Multi-Year Solutions}

Spatial continuous surface deformation may be inferred from pointwise velocities applying geophysical models or geodetic methods based on mathematical interpolation approaches. The approach used in the present study is the least-squares collocation (LSC, e.g., Moritz 1973; Drewes 1978). Previous studies applied also the finite element method used with geophysical models (e.g., Heidbach and Drewes 2003). It has been demonstrated that for the sole representation of the horizontal Earth surface kinematics, the results of both methods are very similar (e.g., Drewes and Heidbach 2005). The vertical deformation is not considered in this work because the station height variations are highly influenced by local effects, and the station distribution (Fig. 1) is too sparse to apply correlations between neighbouring stations. In the modelling of the surface kinematics, we distinguish two components: the velocity field and the deformation model. In the latter one, a secular motion inferred from plate motion estimates (Fig. 1) is removed from the station velocities, and the pointwise residual velocities are interpolated to a regular grid.

The least-squares collocation method is based on the analysis of the correlation of physical quantities between neighbouring points. The vector of the observations (in this case the station velocities) is divided into a systematic part (trend) and two independent random parts: the signal and the observation error (or noise). The parameters describing the systematic component and the stochastically correlated signals are estimated by minimising the noise. The spatial signal correlation is usually assumed as a function depending on the distance $d$ and, presuming isotropy after trend removal, independent of the direction. The basic LSC formula is given by (Drewes and Heidbach 2005, 2012):

$$
\mathbf{v}_{\text {pred }}=\mathbf{C}_{n e w}^{T}\left(\mathbf{C}_{o b s}-\mathbf{C}_{n n}\right)^{-1} \mathbf{v}_{\text {obs }}
$$

$\mathbf{v}_{\text {obs }}$ contains the station velocities obtained from the GNSS observations at the geodetic stations. $\mathbf{v}_{\text {pred }}$ represents the velocities to be predicted at the grid points. $\mathbf{C}_{o b s}$ is the correlation matrix between the observed velocities. $\mathbf{C}_{n e w}$ is the correlation matrix between predicted and observed velocities. $\mathbf{C}_{n n}$ is the noise covariance matrix (it contains the uncertainty of the station velocities obtained within the multi-year solutions). The correlation between the observed velocities $v_{i}, v_{k}$ at the (adjacent) geodetic stations $i, k$ is determined under the stationarity condition over a defined domain by

$$
C_{o b s}\left(d_{i k}\right)=E\left\{v_{i} \cdot v_{k}\right\},
$$

$E$ is the statistical expectation and $d_{i k}$ is the distance between stations $i$ and $k$. The $C_{o b s}$ values are classified in $\Delta d_{j}$ class intervals and the respective cross-covariance $C_{o b s}\left(\Delta d_{j}\right)$ and auto-covariance $C_{o b s}(d=0)=C_{0}$ are determined using:

$$
C_{o b s}\left(\Delta d_{j}\right)=\frac{1}{n_{j}} \sum_{i<k}^{j} v_{i} \times v_{k} ; \quad C_{o b s}(d=0)=C_{0}=\frac{1}{n} \sum_{i=1}^{n} v_{i}^{2},
$$

$n$ stands for the number of stations available at the defined domain, while $n_{j}$ represents the number of stations available at each class interval $\Delta d_{j}$. After estimating the discrete empirical covariance values with Eq. (3), they are approximated by a continuous function $C\left(d_{i k}\right)$, which here is the exponential function:

$$
C\left(d_{i k}\right)=a e^{-b \cdot d_{i k}}
$$

The function parameters $a$ and $b$ are estimated by a leastsquares adjustment. $\mathbf{C}_{o b s}$ is symmetrical and its main diagonal $(i=k)$ contains the values $C_{0}$. Fulfilling the stationarity condition, the elements of $\mathbf{C}_{\text {new }}$ are computed using the same Eq. (4) as a function of the distance between the grid node to be interpolated and the geodetic stations. To satisfy the isotropy condition, we estimate a common rotation vector and remove this horizontal motion trend from all station velocities located in the same domain defined by $d$. Afterwards, we restore the removed trend to the velocities $v_{\text {pred }}$ predicted at the grid points (cf. Drewes 1982, 2009). 

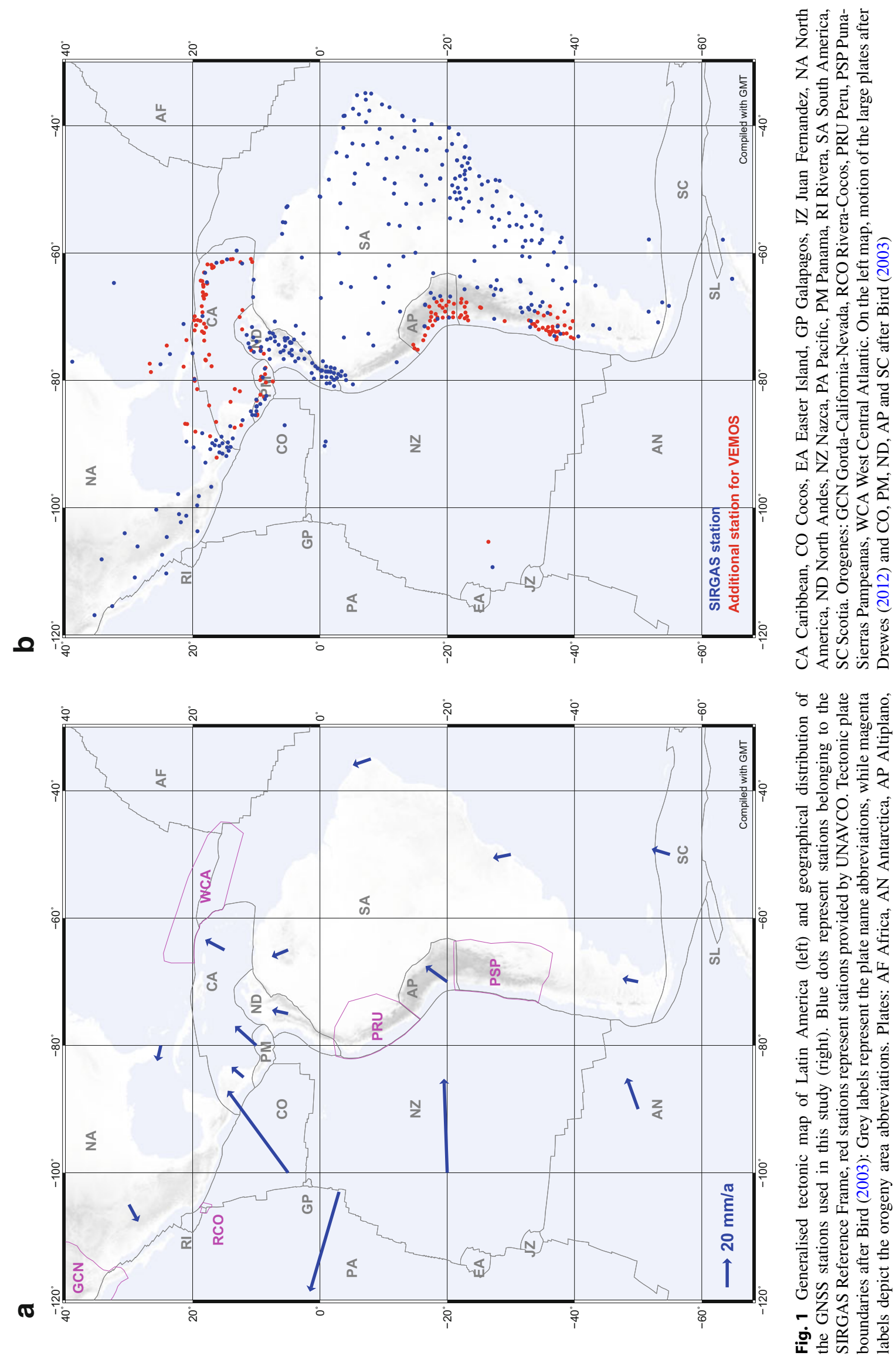


\section{Existing Velocity Models for SIRGAS (VEMOS)}

The first velocity model for SIRGAS (VEMOS) was released in 2003. It is based on the position differences between the two SIRGAS campaigns of 1995 and 2000, 48 velocities derived from the SIRGAS multi-year solution DGF01P01 (Seemüller et al. 2002), and 231 velocities from several geodynamic projects based on episodic GPS campaigns (cf. Drewes and Heidbach 2005). The different data sets were transformed to a common kinematic frame by deriving the rotation vector of the South American plate from the respective station motions located in the rigid part of South America, and reducing these plate motions from the particular data sets. The resulting residual motions were modelled to a continuous deformation field applying the finite element method and LSC approach as described in the previous section. The comparison of the results of both methods shows an agreement in the mm/a level. VEMOS2003 covers the South American area between the latitudes $45^{\circ} \mathrm{S}$ and $12^{\circ} \mathrm{N}$.

The second VEMOS model was released in 2009 (Drewes and Heidbach 2012). It considers 496 station velocities; 95 of them corresponding to the SIRGAS multi-year solution SIR09P01 (Seemüller et al. 2011) and the others derived from repetitive GPS campaigns. It covers the Latin American area between the latitudes $56^{\circ} \mathrm{S}$ and $20^{\circ} \mathrm{N}$ and the time-span from January 2, 2000 to June 30, 2009. The continuous surface velocity field was derived applying the same strategies as in VEMOS2003. The main advantages of VEMOS2009 with respect to VEMOS2003 are the increased number of input velocities, the better quality of measurements (due to an increase of continuously operating GNSS stations), and the extension of the velocity field to the Caribbean and the southernmost part of Chile and Argentina. The mean uncertainty of VEMOS2009 is about $\pm 1.5 \mathrm{~mm} / \mathrm{a}$.

After the Maule earthquake in Feb 2010, the station velocities in the area between latitudes $30^{\circ} \mathrm{S}$ and $40^{\circ} \mathrm{S}$ changed dramatically (Sánchez and Drewes 2016). However, we could not compute a new VEMOS model immediately, because we required 5 years of observations after the earthquake in order to improve the modelling of the strong post-seismic decay signals detected at the affected SIRGAS stations. Consequently, a new VEMOS model was computed in 2015 using the LSC method with station velocities based on GNSS observations captured from March 2010 to March 2015 (VEMOS2015, Sánchez and Drewes 2016). VEMOS2015 is based on continuously operating GNSS stations only; it does not include episodic GPS campaigns. It covers the region from $110^{\circ} \mathrm{W}, 55^{\circ} \mathrm{S}$ to $35^{\circ} \mathrm{W}, 32^{\circ} \mathrm{N}$ with a spatial resolution of $1^{\circ} \times 1^{\circ}$. The average prediction uncertainty is $\pm 0.6 \mathrm{~mm} / \mathrm{a}$ in the north-south direction and $\pm 1.2 \mathrm{~mm} / \mathrm{a}$ in the east-west direction. The maximum uncertainty $( \pm 9 \mathrm{~mm} / \mathrm{a})$ occurs in the Maule deformation zone (Chile), while the minimum $( \pm 0.1 \mathrm{~mm} / \mathrm{a})$ appears in the stable eastern part of the South American plate.

\section{$4 \quad$ Present-Day Deformation Model and Velocity Field for Latin America (VEMOS2017)}

The present study concentrates on the computation of a deformation model based on a set of 515 station velocities inferred from GNSS observations gained from January 2014 to January 2017 (Fig. 2). Station positions and velocities are defined at epoch 2015.0 and refer to the IGS14 Reference Frame (Rebischung 2016), which is based on the latest ITRF solution, the ITRF2014 (Altamimi et al. 2016). The estimated precision is $\pm 1.2 \mathrm{~mm}$ (horizontal) and $\pm 2.5 \mathrm{~mm}$ (vertical) for the station positions at the reference epoch, and $\pm 0.7 \mathrm{~mm} / \mathrm{a}$ (horizontal) and $\pm 1.1 \mathrm{~mm} / \mathrm{a}$ (vertical) for the velocities (Fig. 2). More details about the processing strategy for the determination of the station positions and velocities can be found in Sánchez and Drewes (2016) and Sánchez et al. (2015).

The complex on-going crustal deformation in the western margin of Latin America and the Caribbean has been studied intensively. Recent research concentrates on geophysical syntheses including geodetic constraints inferred from GNSS positioning to model tectonic evolution and associated geodynamic processes in this region. Most of these studies assume a segmentation of the Earth's crust and describe the surface kinematics by means of tectonic blocks or slivers rotating individually; see e.g., Brooks et al. (2011), Calais et al. (2016), Franco et al. (2012), McFarland et al. (2017), Mendoza et al. (2015), Nocquet et al. (2014), Symithe et al. (2015), Weiss et al. (2016), and references herein. This paper presents two main innovations with respect to the abovementioned publications: Firstly, we compute a deformation model for the entire Latin American and Caribbean region and not for isolated areas only. Secondly, we assume a continuous lithosphere deforming under certain kinematic boundary conditions (as suggested by Flesch et al. 2000; Vergnolle et al. 2007; or Copley 2008), without introducing small lithospheric blocks or slivers, which would enforce constraints on the kinematic model. For the collocation procedure, we consider the main tectonic plates South America (SA), Caribbean (CA), and North America (NA) (Fig. 1) according to the tectonic plate boundary model PB2002 (Bird 2003). Based on the velocities obtained in this study for the stations located on the stable part of the plates, we estimate plate rotation vectors following the strategy presented by Drewes $(1982,2009)$. These plate motions are removed from the pointwise velocities to get the residual velocities, which are interpolated to a continuous deformation model 


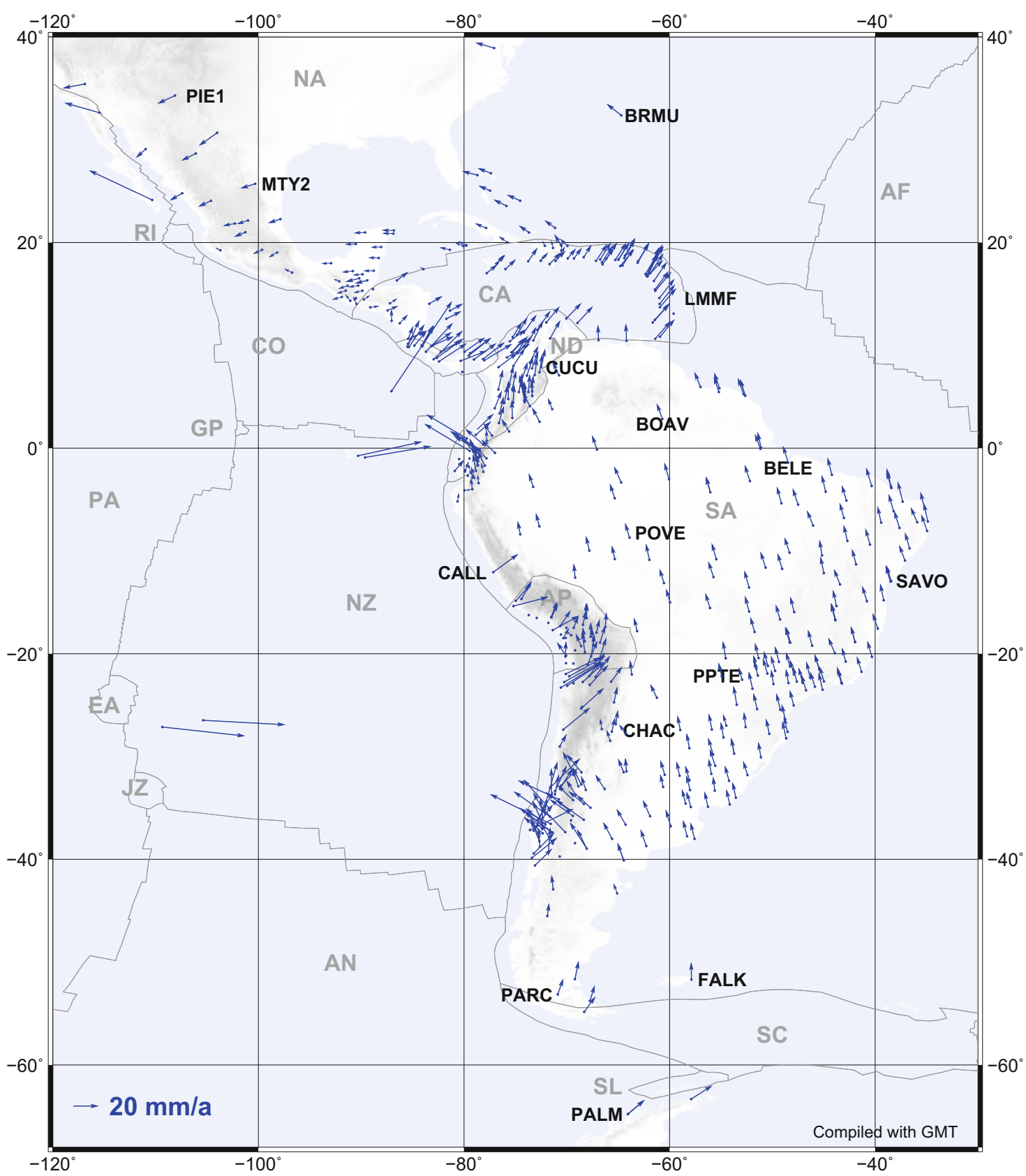

Fig. 2 Horizontal station velocities referring to the IGS14 (ITRF2014). Black labels identify the fiducial stations

using Eqs. (1)-(4). The residual velocities with respect to the Caribbean plate are used for the LSC prediction in Mexico, Central America and the Caribbean (Fig. 3), while the residual velocities with respect to the South American plate are used in South America (Fig. 4). The collocation domain at every grid node is created by selecting the stations located up to a distance of $200 \mathrm{~km}$. If no stations are available at this distance, the LSC is computed using the three nearest stations. In total 2,233 grid points are predicted. Once the LSC prediction is performed, the previously reduced trends (plate rotations) are restored to the interpolated residual velocities at the grid nodes to generate a continuous velocity field referring to the IGS14 (ITRF2014). The average prediction uncertainty is $\pm 1.0 \mathrm{~mm} / \mathrm{a}$ in the north-south direction and $\pm 1.7 \mathrm{~mm} / \mathrm{a}$ in the east-west direction. The maximum uncertainty values (up to $\pm 15 \mathrm{~mm} / \mathrm{a}$ ) occur at the zones affected by recent strong earthquakes, not only in the Maule area but also in the northern part of Chile, Ecuador and Costa Rica. The best uncertainty values (about $\pm 0.1 \mathrm{~mm} / \mathrm{a}$ ) are evident in the stable eastern part of the South American plate. 
a

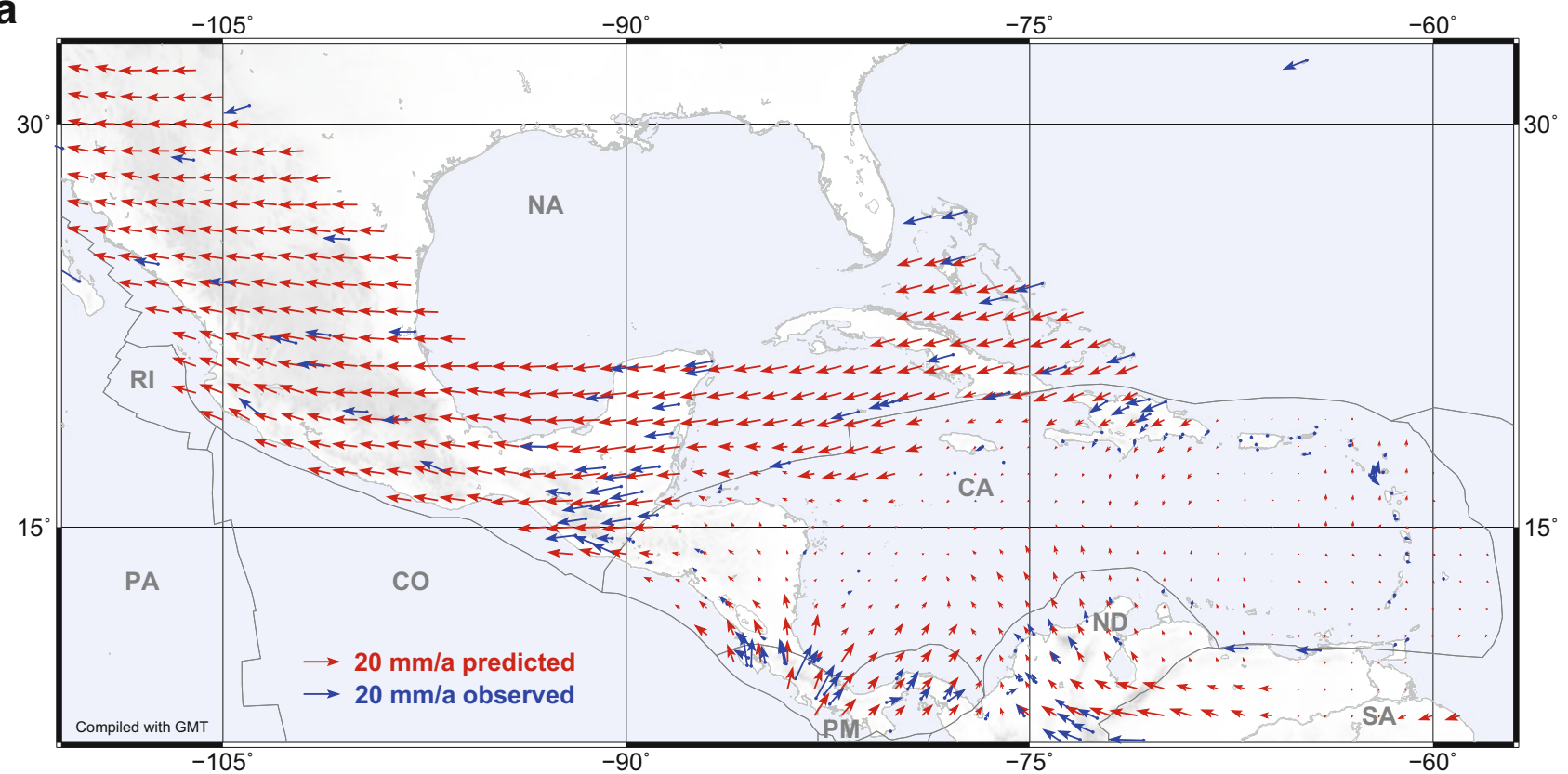

b

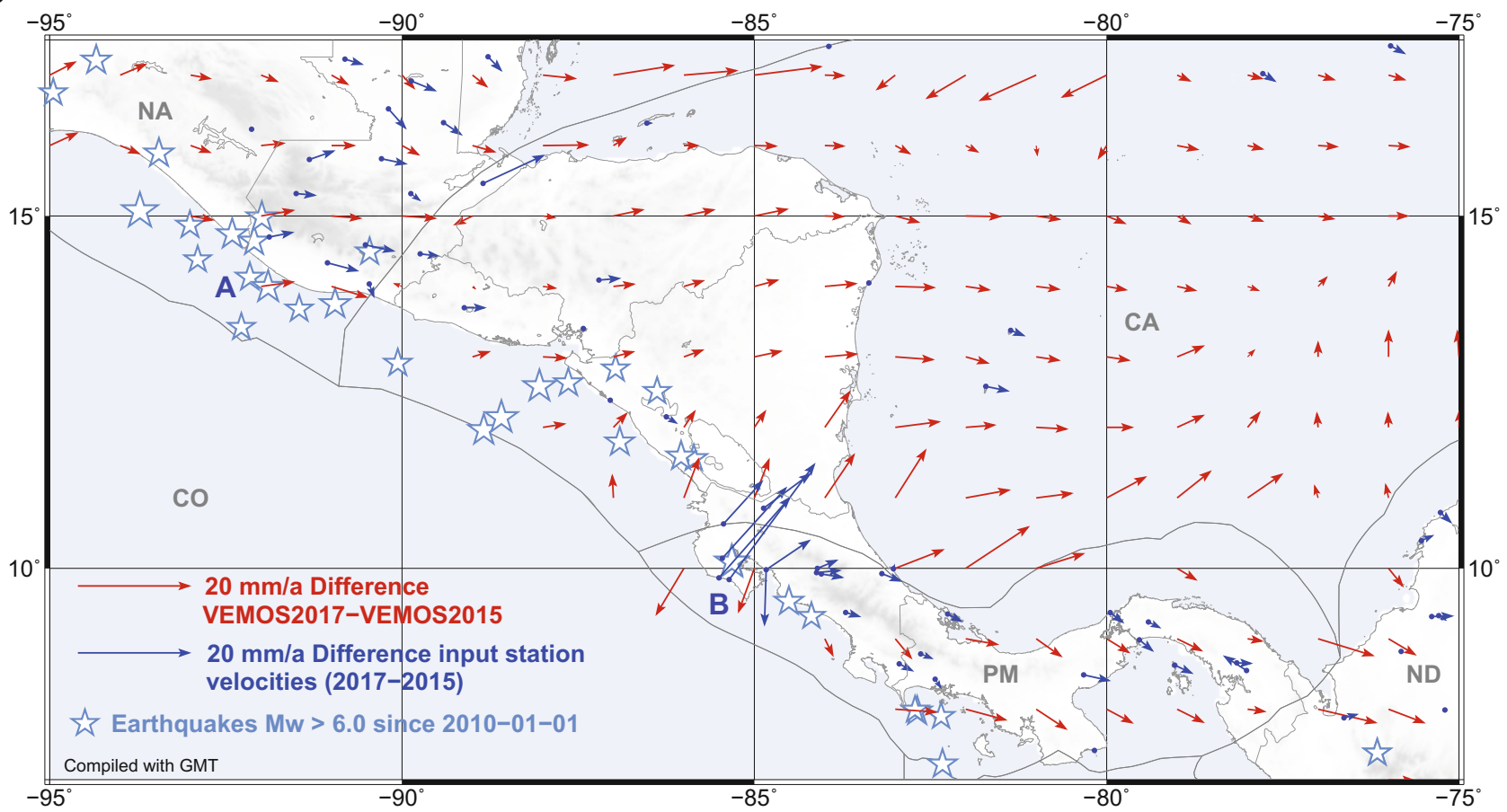

Fig. 3 (a) Surface deformation model VEMOS 2017 relative to the Caribbean plate. Blue vectors represent the input station velocities. (b) Differences of the input station velocities (blue vectors) and the deformation models (red vectors) VEMOS2015 (Sánchez and Drewes 2016) and VEMOS2017 (this study). Stars represent earthquakes with
Mw $>6.0$ occurred since Jan 1, 2010. The large discrepancies appear close to the epicentre of the strong earthquakes in Champerico (Mw7.4) on Nov 11, 2012 (marked with A) and Nicoya (Mw7.6) on Sep 5, 2012 (marked with B) 


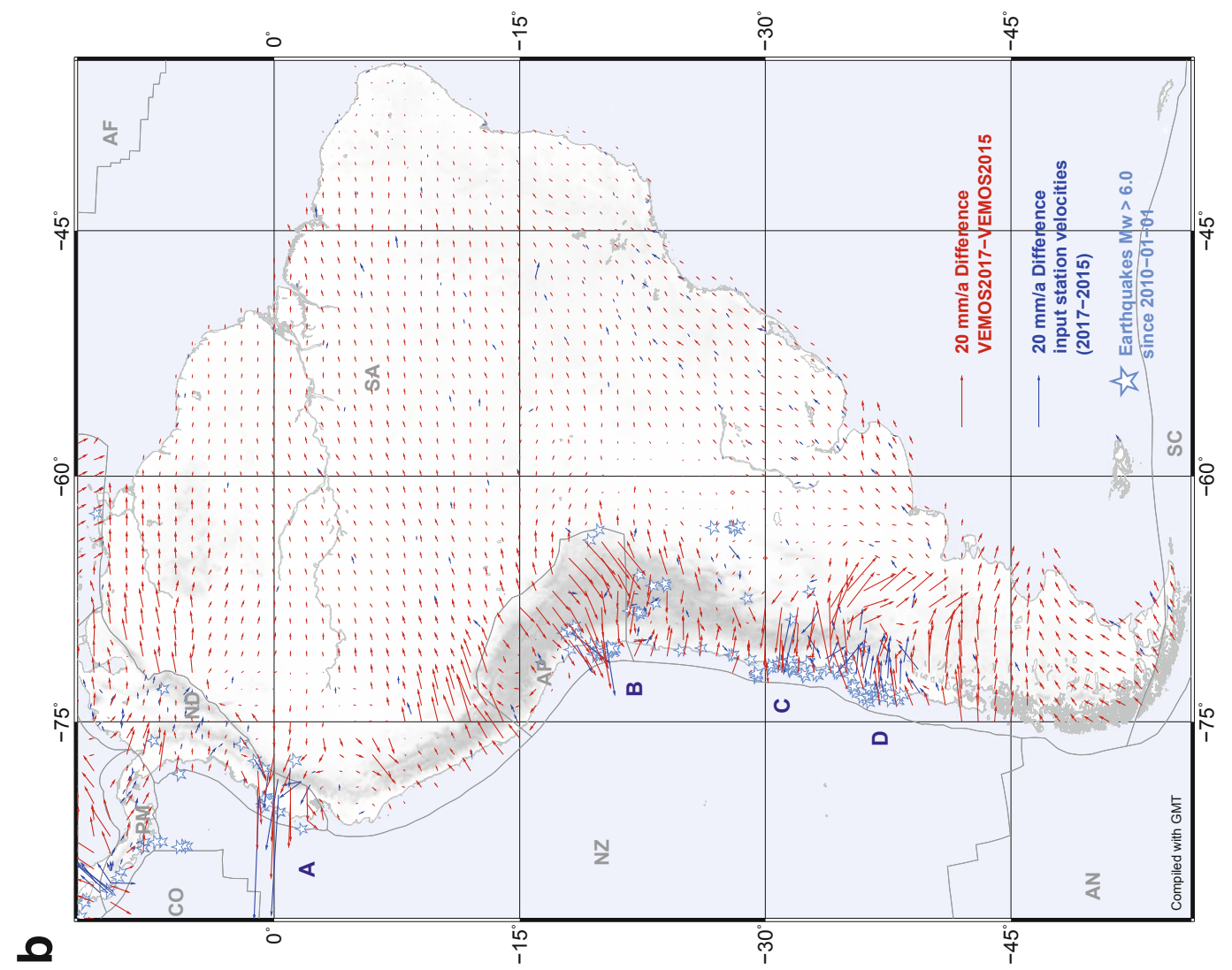

完

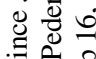

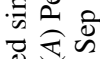

菏

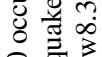

棺

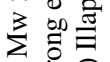

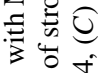

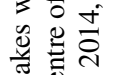

흘

ฮँ

둥

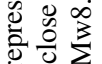

密芯总。

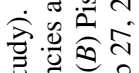

क ⿸丆口

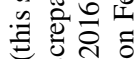

눙

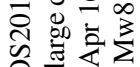

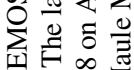

$>\stackrel{\infty}{>}$

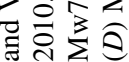

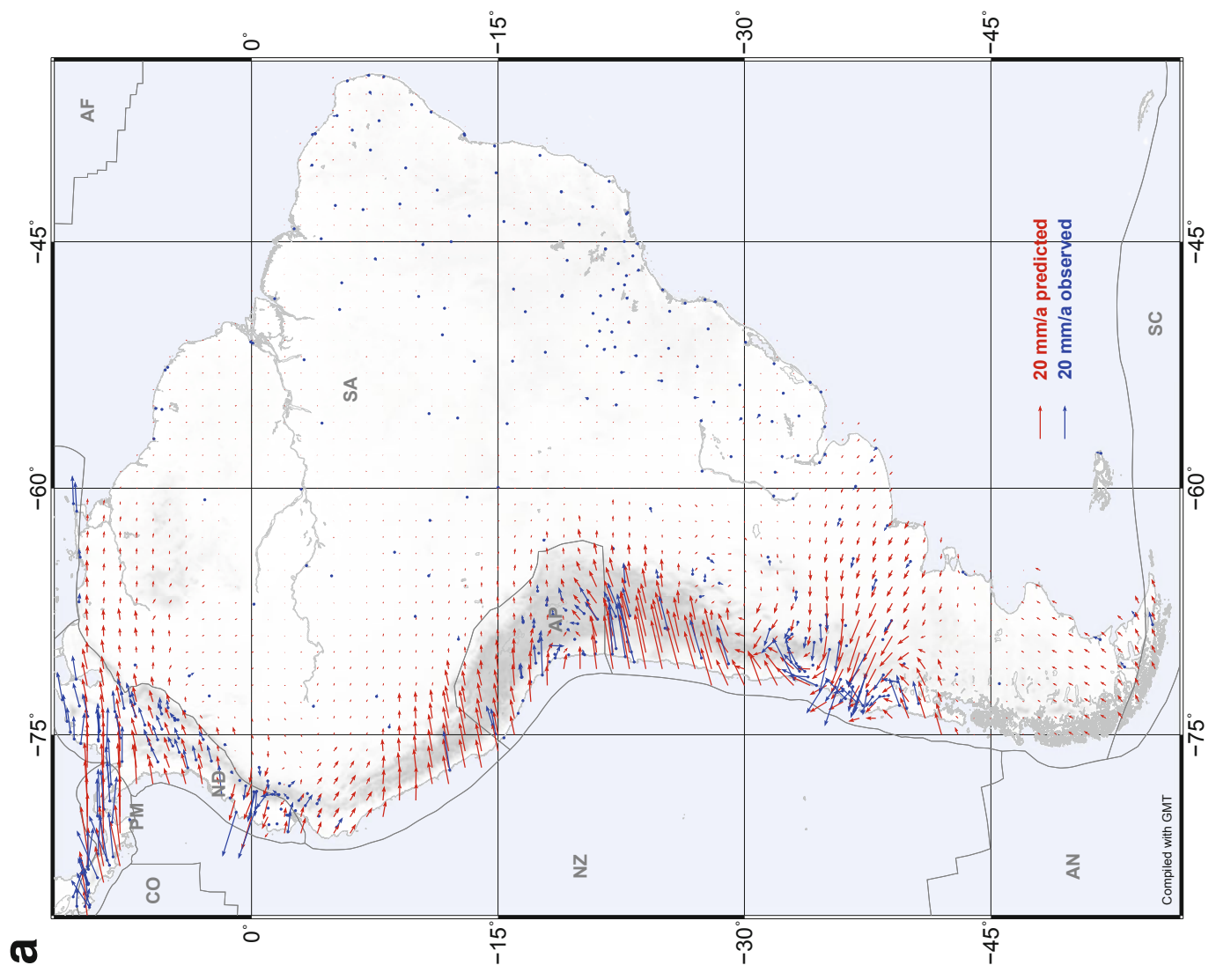

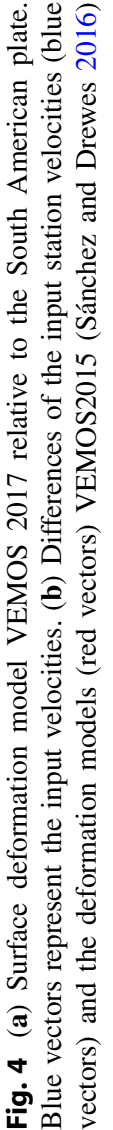




\section{Discussion}

The deformation model with respect to the Caribbean plate (Fig. 3a) shows an inhomogeneous surface kinematics. While the deformation vectors in Puerto Rico and the Lesser Antilles show small (less than $0.5 \mathrm{~mm} / \mathrm{a}$ ) relative motions, the direction of the deformation vectors in Hispaniola describes a southward rotation starting with an orientation of $\mathrm{S} 70^{\circ} \mathrm{W}$ in the northern part and reaching a south orientation in the southernmost part of the island. The magnitude of the vectors also decreases with this rotation: the averaged deformation is about $12 \mathrm{~mm} / \mathrm{a}$ in the North and less than $1 \mathrm{~mm} / \mathrm{a}$ in the South. These deformation patterns are in agreement with the GPS results published in earlier studies, e.g.; Benford et al. (2012), Symithe et al. (2015), Calais et al. (2016). In the southern area of Central America (Panama block), we observe horizontal deformations in the range $5-15 \mathrm{~mm} / \mathrm{a}$ relative to the Caribbean plate. These large magnitudes are dominated in the West by the north-eastward motion of the Cocos plate towards Central America (see Fig. 3a around longitude $84^{\circ} \mathrm{W}$ ) and in the East by the eastern motion of the Nazca plate towards South America (see Fig. 3a around longitude $78^{\circ} \mathrm{W}$ ). A progressive westward rotation of the deformation vectors toward the North American plate is detected over Nicaragua and Honduras (longitudes from $85^{\circ} \mathrm{W}$ to $90^{\circ} \mathrm{W}$ ), where the very small magnitudes of the deformation vectors suggest that this region moves homogeneously with the Caribbean plate.

Figure $3 \mathrm{~b}$ presents the differences between this model (VEMOS2017) and the previous one (VEMOS2015). The largest differences in magnitude (about $12 \mathrm{~mm} / \mathrm{a}$ ) are a consequence of post-seismic displacement and station velocity changes caused by the strong earthquake of Nicoya (Mw 7.6, Sep 5, 2012), Costa Rica, (marked with B in Fig. $3 b)$. This earthquake produced co-seismic displacements up to $30 \mathrm{~cm}$ at the GNSS stations located in the Peninsula Nicoya (see Fig. 9 in Sánchez and Drewes 2016). The postseismic relaxation process induces pre- and post-seismic station velocity differences up to $30 \mathrm{~mm} / \mathrm{a}$. Another relevant discrepancy between VEMOS2017 and VEMOS2015 is observed in Guatemala (marked with A in Fig. 4). In this case, the difference in the deformation magnitude (about $5 \mathrm{~mm} / \mathrm{a}$ ) is mainly caused by the Champerico earthquake (Mw 7.4, Nov 11, 2012).

The deformation model with respect to the South American plate (Fig. 4a) clearly defines the stable area belonging to the Guiana, Brazilian and Atlantic shields. Indeed, the present VEMOS2017 and the previous model VEMOS2015 are practically identical in this area (Fig. 4b). In contrast, the deformation vectors predicted in the Andean region are characterized by magnitudes up to $30 \mathrm{~mm} / \mathrm{a}$. These vectors are roughly parallel to the plate subduction direction and their magnitudes diminish with the distance from the subduction front as already stated by previous publications like Bevis et al. (2001), Brooks et al. (2011), Chlieh et al. (2011), Khazaradze and Klotz (2003) and references herein. However, we observe three zones with anomalous vector directions (oriented to the NW): the western part of Ecuador around latitude zero, the north of Chile around latitude $20^{\circ} \mathrm{S}$, and the Maule region (around $38^{\circ} \mathrm{S}$ ). As in the case of Central America, these abnormalities are also caused by recent strong earthquakes and post-seismic relaxations (Fig. 4b).

The surface deformation predicted for the North Andes (ND) block is characterized by two different kinematic patterns: a north-eastward motion with increasing magnitudes of about $9 \mathrm{~mm} / \mathrm{a}$ in the southern part of Colombia (latitude $3^{\circ} \mathrm{N}$ ) to $15 \mathrm{~mm} / \mathrm{a}$ in the northern border area with Venezuela $\left(72^{\circ} \mathrm{W}, 12^{\circ} \mathrm{N}\right)$; and opposite oriented deformation vectors in Ecuador (south of latitude $3^{\circ} \mathrm{S}$ ). The latter is a consequence of the strong earthquake occurred in Pedernales ( $\mathrm{Mw}$ 7.8) on Apr 16, 2016. This earthquake produced co-seismic station displacements up to $80 \mathrm{~cm}$ and station velocity changes of about $40 \mathrm{~mm} / \mathrm{a}$ (see Fig. 4b, mark A). The differences between VEMOS2017 and VEMOS2015 in this area come up to $22 \mathrm{~mm} / \mathrm{a}$. South of this region, the poor station coverage in central Peru (latitudes $5^{\circ} \mathrm{S}$ to $12^{\circ} \mathrm{S}$ ) prevents concluding statements about the deformation pattern in this area; however, our model agrees quite well with the findings published by Nocquet et al. (2014) and Villegas-Lanza (2014). Based on about 100 GNSS stations covering the area between latitudes $12^{\circ} \mathrm{S}$ and $4.6^{\circ} \mathrm{N}$, they conclude that the southern Ecuadorian Andes and northern Peru (between latitudes $5^{\circ} \mathrm{S}$ and $10^{\circ} \mathrm{S}$ ) move coherently $5-6 \mathrm{~mm} / \mathrm{a}$ with an orientation of about $\mathrm{S} 70^{\circ} \mathrm{E}$. They also suggest that the internal deformation in this area is negligible (see Fig. 2a in Nocquet et al. 2014).

South of latitude $15^{\circ} \mathrm{S}$ the deformation model (Fig. 4a) and its comparison with the previous one (Fig. 4b) are highly influenced by three major earthquakes: Pisagua (Mw8.2) on Apr 1, 2014, Illapel (Mw8.3) on Sep 16, 2015, and Maule (Mw8.8) on Feb 27, 2010. Before the Pisagua earthquake, the GNSS stations moved about $27 \mathrm{~mm} / \mathrm{a}$ N $45^{\circ} \mathrm{E}$; after the earthquake, they are moving $5 \mathrm{~mm} / \mathrm{a}$ to the North (see ITRF-related station velocities in Fig. 2). This produces an apparent smaller deformation with respect to the South American plate and the differences between both VEMOS models reach magnitudes up to $20 \mathrm{~mm} / \mathrm{a}$ (mark B in Fig. 4b). In the area Illapel (mark C in Fig. 4b), the postseismic effects of the 2015 earthquake superimpose the post-seismic effects of the 2010 Maule earthquake (mark D in Fig. 4b). Thus, it is not possible to distinguish their 
individual contributions to the deformation. As a matter of fact, the complex kinematic pattern south of latitude $25^{\circ} \mathrm{S}$ described by Sánchez and Drewes (2016, Fig. 18) persists. A large counter clockwise rotation around a point south of the 2010 epicentre $\left(35.9^{\circ} \mathrm{S}, 72.7^{\circ} \mathrm{W}\right)$ and a clockwise rotation north of the epicentre are further observed (Fig. 4a). However, magnitude and direction of the deformation vectors considerably differ from those obtained in the previous model VEMOS2015. This is probably a consequence of the post-seismic relaxation process that is bringing the uppermost crust layer to the aseismic NE motion in this zone as suggested by e.g., Bedford et al. (2016), Klein et al. (2016) and Li et al. (2017). The surface kinematics shown in Fig. 4a again makes evident that the deformation regime imposed by the Maule earthquake reaches the Atlantic coast in Argentina. The comparison of the present deformation model with VEMOS2015 in the Maule surroundings presents discrepancies up to $25 \mathrm{~mm} / \mathrm{a}$ (marks C and D in Fig. 4b). To provide an integrated view of the changing surfacekinematics in the Andean Region, Fig. 5 presents an extract of the models VEMOS2003, VEMOS2009, VEMOS2015 and VEMOS2017.

\section{Conclusions and Outlook}

This paper presents the surface velocity and deformation models of the entire Latin American and Caribbean region over the time-span 2014-2017 and describes the evolution of the models from previous studies. The effects of the extreme changes in the surface kinematics complicate the long-term stability expected in any reference frame. Therefore, a major recommendation is to materialise the geodetic reference frames by means of a dense network of continuously operating stations and to repeat the velocity computations frequently. This ensures a permanent monitoring of possible reference frame deformations. Nevertheless, a reliable deformation modelling is not yet guaranteed. Some authors suggest the implementation of geodynamic models to predict the pointwise coordinate changes caused by coseismic and post-seismic effects (see e.g., Snay et al. 2013; Bevis and Brown 2014; Gómez et al. 2015). Since these models rely on hypotheses about the physical properties of the upper Earth crust, different hypotheses produce different results as demonstrated by e.g., Li et al. (2017). We based our analyses on the least-squares collocation as this approach respects the consistency of the geodetic observations and ensures a better agreement with the actual deformation. A problem in the geodetic use of pointwise velocities derived from multi-year solutions is their inconsistency after seismic events, i.e. their short-term validity. In the Andes region, like in any active seismic region of the Earth, there are large discontinuities in the station coordinate time series and considerable variations in the station velocities caused by strong earthquakes. The consequence is that the respective reference frames (e.g., ITRF) cannot be used or have to be frequently updated for geodetic purposes (like SIRGAS). An alternative of using multi-year solutions with station velocities is the release of frequent reference frames (e.g., every week or month). Our recommendation for the SIRGAS national reference frames in seismic active regions is to use the SIRGAS weekly coordinate solutions instead of velocities after seismic events. To consider discontinuities in the coordinates of non-permanently observed points, one has to interpolate them from the coordinate differences in reference stations. In any case, we shall continue the computation of short-period velocity and deformation models for the next future in order to enable the use of coordinates in close alignment with to the IGS reference frames.

\section{Supplementary Data}

In the preparation of the GNSS data solutions used in this study, we computed a new SIRGAS reference frame solution following the same procedure described in Sánchez and Drewes (2016). This solution, called SIR17P01, covers the time-span from April 17, 2011 to January 28, 2017, contains 345 SIRGAS stations with 502 occupations and is aligned to IGS14, epoch 2015.0. The SIR17P01 station positions and velocities as well as the VEMOS2017 model (velocity and deformation fields) are available at https://doi.pangaea.de/ 10.1594/PANGAEA.912349 and https://doi.pangaea.de/10. 1594/PANGAEA.912350, respectively.

Acknowledgments We are much obliged to SIRGAS for providing us with the weekly normal equations of the SIRGAS reference network (ftp://ftp.sirgas.org/pub/gps/SIRGAS/). They are the primary input of this study. We are also grateful to the International GNSS Service (IGS, Johnston et al. 2017) and UNAVCO for making available some of the invaluable GNSS data sets used in this study (see red dots in Fig. 1). The GNSS data analysis and the computation of the multi-year solution presented in this work were accomplished with the Bernese GNSS Software version 5.2 (Dach et al. 2015). The maps were compiled with the Generic Mapping Tools (GMT) software package version 5.1.1 (Wessel et al. 2013). The topography represented on the maps corresponds to the ETOPO1 dataset (Amante and Eakins 2009). 

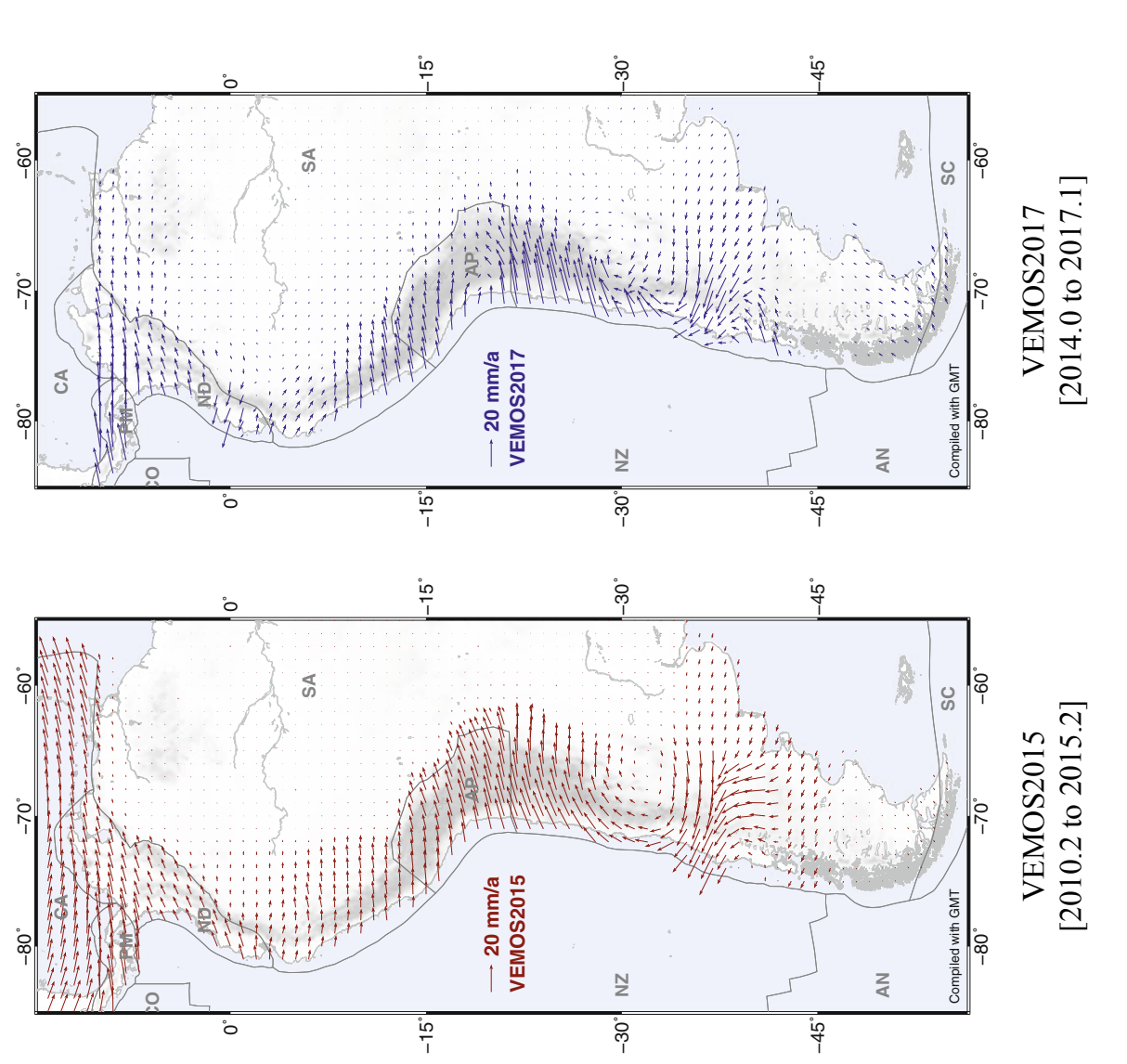

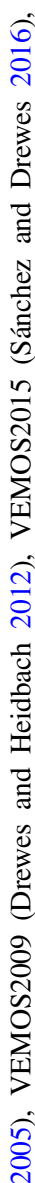
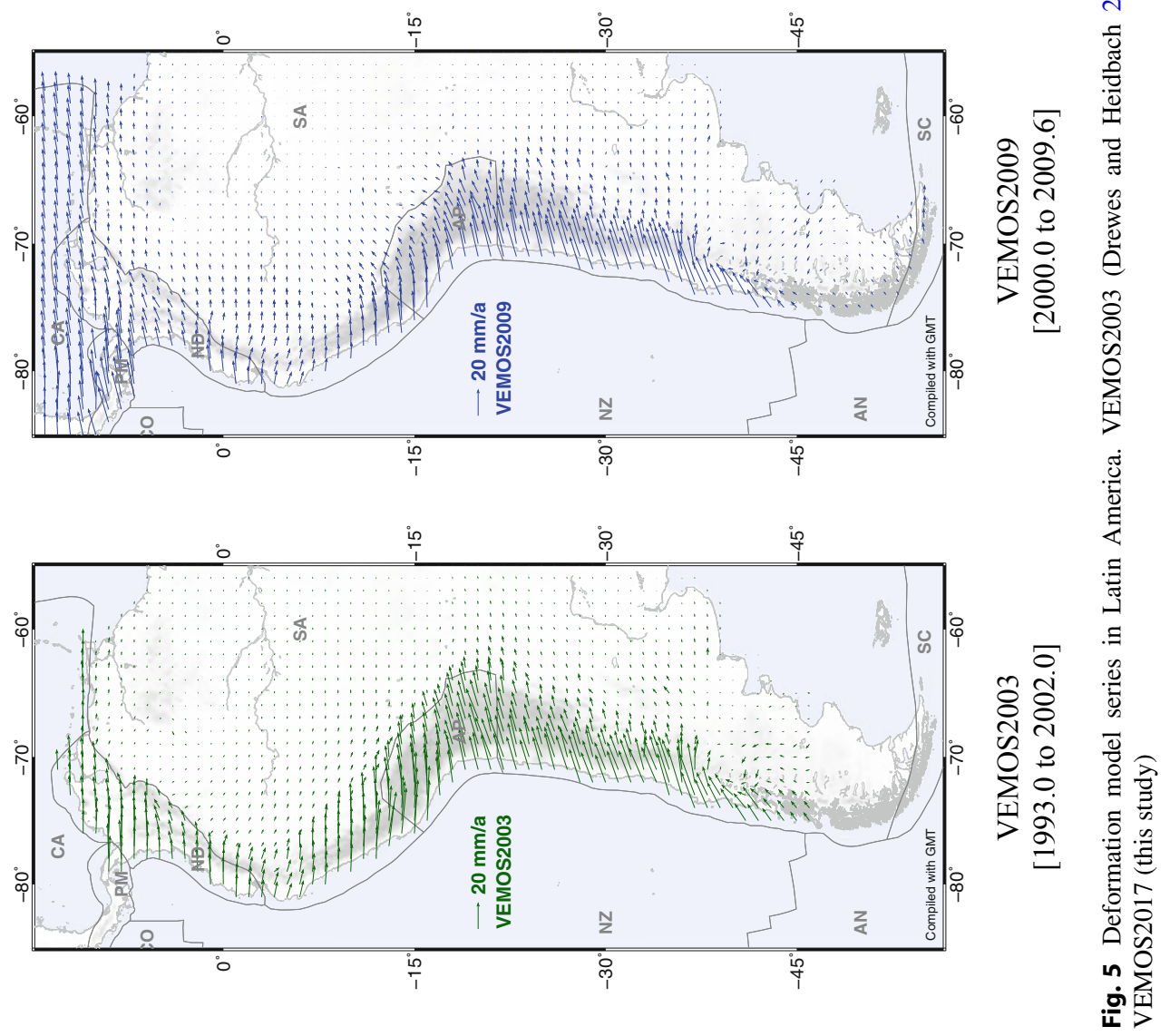


\section{References}

Altamimi Z, Rebischung P, Métivier L, Collilieux X (2016) ITRF2014: A new release of the International Terrestrial Reference Frame modeling nonlinear station motions. J Geophys Res Solid Earth 121:6109-6131. https://doi.org/10.1002/2016JB013098

Amante C, Eakins BW (2009) ETOPO1 Global Relief Model converted to PanMap layer format. NOAA-National Geophysical Data Center, PANGAEA. https://doi.org/10.1594/PANGAEA.769615

Bedford J, Moreno M, Li S, Oncken O, Baez JC, Bevis M, Heidbach O, Lange D (2016) Separating rapid relocking, afterslip, and viscoelastic relaxation: an application of the postseismic straightening method to the Maule 2010 cGPS. J Geophys Res Solid Earth 121:7618-7638. https://doi.org/10.1002/2016JB013093

Benford B, DeMets C, Calais E (2012) GPS estimates of microplate motions, northern Caribbean: evidence for a Hispaniola microplate and implications for earthquake hazard. Geophys J Int 191(2):481490. https://doi.org/10.1111/j.1365-246X.2012.05662.x

Bevis M, Brown A (2014) Trajectory models and reference frames for crustal motion geodesy. J Geod 88:283-311. https://doi.org/10.1007/ s00190-013-0685-5

Bevis M, Kendrick E, Smalley R Jr, Brooks BA, Allmendinger RW, Isacks BL (2001) On the strength of interpolate coupling and the rate of back arc convergence in the central Andes: an analysis of the interseismic velocity field. Geochem Geophys Geosyst 2:1067. https://doi.org/10.1029/2001GC000198

Bird P (2003) An updated digital model for plate boundaries. Geochem Geophys Geosyst 4(3):1027. https://doi.org/10.1029/ 2001GC000252

Brooks BA, Bevis M, Whipple K, Arrowsmith JR, Foster J, Zapata T, Kendrick E, Minaya E, Echalar A, Blanco M, Euillades P, Sandoval M, Smalley RJ (2011) Orogenic-wedge deformation and potential for great earthquakes in the central Andean backarc. Nat Geosci 4:380-383. https://doi.org/10.1038/ngeo1143

Brunini C, Sánchez L, Drewes H, Costa SMA, Mackern V, Martinez W, Seemüller W, Da Silva AL (2012) Improved analysis strategy and accessibility of the SIRGAS reference frame. In: Kenyon S, Pacino MC, Marti U (eds) Geodesy for planet earth, vol 136, IAG symposia, pp 3-10. https://doi.org/10.1007/978-3-642-20338-1_1

Calais E, Symithe S, de Lépinay BM, Prépetit C (2016) Plate boundary segmentation in the north-eastern Caribbean from geodetic measurements and Neogene geological observations. C.R. Geosci 348:4251. https://doi.org/10.1016/j.crte.2015.10.007

Chlieh M, Perfettini H, Tavera H, Avouac J-P, Remy D, Nocquet J-M, Rolandone F, Bondoux F, Gabalda G, Bonvalot S (2011) Interseismic coupling and seismic potential along the Central Andes subduction zone. J Geophys Res 116:B12405. https://doi.org/10. 1029/2010JB008166

Cioce V, Martínez W, Mackern MV, Pérez R, De Freitas S (2018) SIRGAS: Reference frame in Latin America. Coordinates XIV(6):610

Copley A (2008) Kinematics and dynamics of the southeastern margin of the Tibetan Plateau. Geophys J Int 174(3):1081-1100. https://doi. org/10.1111/j.1365-246X.2008.03853.x

Dach R, Lutz S, Walser P, Fridez P (eds) (2015) Bernese GNSS Software Version 5.2. Astronomical Institute, University of Bern

Drewes H (1978) Experiences with least squares collocation as applied to interpolation of geodetic and geophysical quantities. Proceedings 12th symposium on Mathematical Geophysics. Caracas, Venezuela

Drewes H (1982) A geodetic approach for the recovery of global kinematic plate parameters. Bull Geod 56:70-79. https://doi.org/10. 1007/BF02525609

Drewes H (2009) The actual plate kinematic and crustal deformation model APKIM2005 as basis for a non-rotating ITRF. In: Drewes H (ed) Geodetic reference frames, IAG symposia, vol 134, pp 95-99. https://doi.org/10.1007/978-3-642-00860-3_15
Drewes H (2012) Current activities of the International Association of Geodesy (IAG) as the successor organisation of the Mitteleuropäische Gradmessung. Z. f. Verm.wesen (zfv) 137:175-184

Drewes H, Heidbach O (2005) Deformation of the South American crust estimated from finite element and collocation methods. In: Sansò F (ed) A window on the future of geodesy, IAG symposia, vol 128, pp 544-549. https://doi.org/10.1007/3-540-27432-4_92

Drewes H, Heidbach O (2012) The 2009 horizontal velocity field for South America and the Caribbean. In: Kenyon S, Pacino MC, Marti U (eds) Geodesy for planet earth, vol 136, IAG symposia, pp 657-664. https://doi.org/10.1007/978-3-642-20338$1 \_81$

Drewes H, Kaniuth K, Voelksen C, Alves Costa SM, Souto Fortes LP (2005) Results of the SIRGAS campaign 2000 and coordinates variations with respect to the 1995 South American geocentric reference frame. In: A window on the future of geodesy, vol 128, IAG symposia, pp 32-37. https://doi.org/10.1007/3-540-27432-4_6

Flesch LM, Holt WE, Haines AJ, Bingming S-TB (2000) Dynamics of the Pacific-North American Plate Boundary in the Western United States. Science 287(5454):834-836. https://doi.org/10.1126/science. 287.5454.834

Franco A, Lasserre C, Lyon-Caen H, Kostoglodov V, Molina E, Guzman-Speziale M, Monterosso D, Robles V, Figueroa C, Amaya W, Barrier E, Chiquin L, Moran S, Flores O, Romero J, Santiago JA, Manea M, Manea VC (2012) Fault kinematics in northern Central America and coupling along the subduction interface of the Cocos Plate, from GPS data in Chiapas (Mexico), Guatemala and El Salvador. Geophys J Int 189(3):1223-1236. https://doi.org/10.1111/ j.1365-246X.2012.05390.x

Gómez DD, Piñón DA, Smalley R, Bevis M, Cimbaro SR, Lenzano LE, Barónet J (2015) Reference frame access under the effects of great earthquakes: a least squares collocation approach for nonsecular post-seismic evolution. J Geod 90(3):263-273. https://doi. org/10.1007/s00190-015-0871-8

Heidbach O, Drewes H (2003) 3-D finite element model of major tectonic processes in the Eastern Mediterranean. Geol Soc Spec Publs 212:261-274. https://doi.org/10.1144/GSL.SP.2003.212.01.17

Johnston G, Riddell A, Hausler G (2017) The International GNSS Service. In: Teunissen PJG, Montenbruck O (eds) Handbook of global navigation satellite systems, 1st edn. Springer, Cham, pp 967982. https://doi.org/10.1007/978-3-319-42928-1

Khazaradze G, Klotz J (2003) Short- and long-term effects of GPS measured crustal deformation rates along the south central Andes. J Geophys Res 108(B6):2289. https://doi.org/10.1029/2002JB001879

Klein E, Fleitout L, Vigny C, Garaud JD (2016) Afterslip and viscoelastic relaxation model inferred from the large-scale post-seismic deformation following the $2010 \mathrm{M}_{\mathrm{w}} 8.8$ Maule earthquake (Chile). Geophys J Int 205(3):1455-1472. https://doi.org/10.1093/gji/ggw086

Li S, Moreno M, Bedford J, Rosenau M, Heidbach O, Melnick D, Oncken O (2017) Postseismic uplift of the Andes following the 2010 Maule earthquake: implications for mantle rheology. Geophys Res Lett 44(4):1768-1776. https://doi.org/10.1002/2016GL071995

McFarland PK, Bennett RA, Alvarado P, DeCelles PG (2017) Rapid geodetic shortening across the Eastern Cordillera of NW Argentina observed by the Puna-Andes GPS Array. J Geophys Res 122:86008623. https://doi.org/10.1002/2017JB014739

Mendoza L, Richter A, Fritsche M, Hormaechea JL, Perdomoa R, Dietrich R (2015) Block modeling of crustal deformation in Tierra del Fuego from GNSS velocities. Tectonophysics 651-652:58-65. https://doi.org/10.1016/j.tecto.2015.03.013

Moritz H (1973) Least squares collocation. Dt Geod Komm, Nr. A 75

Nocquet J-M, Villegas-Lanza JV, Chlieh M, Mothes PA, Rolandone F, Jarrin P, Cisneros D, Alvarado A, Audin L, Bondoux F, Martin X, Font Y, Régnier M, Vallée M, Tran T, Beauval C, Maguiña Mendoza JM, Martinez W, Tavera H, Yepes H (2014) Motion of continental slivers and creeping subduction in the northern Andes. Nat Geosci 7:287-291. https://doi.org/10.1038/ngeo2099 
Petit G, Luzum B (eds) (2010) IERS Conventions 2010. IERS technical note 36. Verlag des Bundesamtes für Kartographie und Geodäsie, Frankfurt a.M.

Rebischung P (2016) [IGSMAIL-7399] Upcoming switch to IGS14/igs14.atx. https://lists.igs.org/pipermail/igsmail/2016/ 001233.html. Accessed 9 May 2017

Sánchez L, Drewes H (2016) Crustal deformation and surface kinematics after the 2010 earthquakes in Latin America. J Geodyn 102:1-23. https://doi.org/10.1016/j.jog.2016.06.005

Sánchez L, Seemüller W, Drewes H, Mateo L, González G, Silva A, Pampillón J, Martinez W, Cioce V, Cisneros D, Cimbaro S (2013) Long-term stability of the SIRGAS reference frame and episodic station movements caused by the seismic activity in the SIRGAS region. IAG Symposia 138:153-161. https://doi.org/10.1007/978-3642-32998-2_24

Sánchez L, Drewes H, Brunini C, Mackern MV, Martínez-Díaz W (2015) SIRGAS Core Network Stability. In: Rizos C, Willis P (eds) IAG 150 years, vol 143, IAG symposia, pp 183-190. https://doi.org/ 10.1007/1345_2015_143

Seemüller W, Kaniuth K, Drewes H (2002) Velocity estimates of IGS RNAAC SIRGAS stations. In: Drewes H, Dodson A, Fortes LP, Sánchez L, Sandoval P (eds) Vertical reference systems, vol 124, IAG symposia, pp 7-10. https://doi.org/10.1007/978-3-662-046838 2 2

Seemüller W, Sánchez L, Seitz M (2011) The new multi-year position and velocity solution SIR09P01 of the IGS Regional Network Associate Analysis Centre (IGS RNAAC SIR). In: Pacino C et al (eds) Geodesy for planet earth, vol 136, IAG symposia, pp 675-680. https://doi.org/10.1007/978-3-642-20338-1_110
SIRGAS (1997) SIRGAS Final Report; Working Groups I and II IBGE, Rio de Janeiro; 96 p. http://www.sirgas.org/fileadmin/docs/ SIRGAS95RepEng.pdf. Accessed 9 May 2017

Snay RA, Freymueller JT, Pearson C (2013) Crustal motion models developed for version 3.2 of the horizontal time-dependent positioning utility. J Appl Geod. https://doi.org/10.1515/jag-2013-0005

Symithe S, Calais E, de Chabalier JB, Robertson R, Higgins M (2015) Current block motions and strain accumulation on active faults in the Caribbean. J Geophys Res 120:3748-3774. https://doi.org/10.1002/ 2014JB011779

Vergnolle M, Calais E, Dong L (2007) Dynamics of continental deformation in Asia. J Geophys Res 112:B11403. https://doi.org/10.1029/ 2006JB004807

Villegas-Lanza JC (2014) Earthquake cycle and continental deformation along the Peruvian subduction zone. Dissertation, Universite de Nice Sophia Antipolis - UFR Sciences, Ecole Doctorale des Sciences Fondamentales et Appliquées

Weiss JR, Brooks BA, Foster JH, Bevis M, Echalar A, Caccamise D, Heck J, Kendrick E, Ahlgren K, Raleigh D, Smalley R, Vergani G (2016) Isolating active orogenic wedge deformation in the southern Subandes of Bolivia. J Geophys Res Solid Earth 121:6192-6218. https://doi.org/10.1002/2016JB013145

Wessel P, Smith WHF, Scharroo R, Luis JF, Wobbe F (2013) Generic Mapping Tools: Improved version released. EOS Trans AGU 94:409-410

Open Access This chapter is licensed under the terms of the Creative Commons Attribution 4.0 International License (http://creativecommons.org/ licenses/by/4.0/), which permits use, sharing, adaptation, distribution and reproduction in any medium or format, as long as you give appropriate credit to the original author(s) and the source, provide a link to the Creative Commons licence and indicate if changes were made.

The images or other third party material in this chapter are included in the chapter's Creative Commons licence, unless indicated otherwise in a credit line to the material. If material is not included in the chapter's Creative Commons licence and your intended use is not permitted by statutory regulation or exceeds the permitted use, you will need to obtain permission directly from the copyright holder.

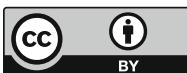

